\title{
Classical Definitions of Gravitation, Electricity and Magnetism
}

\author{
Ogaba Philip Obande ${ }^{1}$ \\ ${ }^{1}$ Department of Chemistry, Ahmadu Bello University, Samaru 810261, Zaria, Nigeria \\ Correspondence: Ogaba Philip Obande, Department of Chemistry, Ahmadu Bello University, Samaru 810261, \\ Zaria, Nigeria. E-mail: gababands@gmail.com
}

$\begin{array}{lc}\text { Received: October 18, } 2015 & \text { Accepted: October 30, } 2015 \text { Online Published: November 19, } 2015 \\ \text { doi:10.5539/apr.v7n6p85 } & \text { URL: http://dx.doi.org/10.5539/apr.v7n6p85 }\end{array}$

\begin{abstract}
In further demonstration of simultaneous existence of the atom as wave and particle, we reproduce values of a number of physical constants using the classical mass equation $\mathrm{h} \vartheta=\mathrm{mc}^{2}$. Most, possibly all, physical constants are coefficients of linear correlations of parameters of the intrinsic electromagnetic (e-m) oscillation that defines the atom; for example: (i) angular frequency per unit radius $\omega / \mathrm{r}$ correlates with rotational strain $\tau$ to produce the effect identified with atomic mass; (ii) the atomic waveform's e-m flux density $\rho_{\mathrm{w}}$ correlates with its radius $r_{w}$ and with the field modulus $\epsilon_{\mathrm{w}}$ to produce the effect associated with Newtonian Gravitation G; (iii) universal (Galilean) gravitational acceleration $g$ arises from correlations of (a) the particulate atom's centripetal force $F_{p}$ with its mass $m_{p}$, (b) the material density $\rho_{p}$ with radius $r_{p}$ and (c) the field (i.e., waveform) modulus $\epsilon_{w}$ with stress $\sigma_{\mathrm{w}}$; (iv) the particulate atom's modulus correlates with its stress field to define the electric constant or permittivity; (v) the waveform (i.e., field) centripetal force $F_{w}$ correlates with strain $\tau_{w}$ to give electron magnetic moment $\mu_{\mathrm{e}}$ and $\tau_{\mathrm{w}}$ correlates with $\omega / \mathrm{r}$ to define electrostatic atomic mass unit amu/eV; (vi) the particulate atom's mass $\mathrm{m}_{\mathrm{p}}$ correlates with density $\rho_{\mathrm{p}}$ to produce the effect associated with magnetic flux density B and (vii) a universal invariant waveform gravitational (centripetal) acceleration $\mathrm{g}=7.9433 \times 10^{59} \mathrm{~m} \mathrm{~s}^{-2} \mathrm{~kg}^{-1}$ binds matter together on atomic, stellar, galactic and cosmic scales, it is identifiable with the strong nuclear force (SNF) suggesting that the SNF is not electromagnetic but mechanical. The investigation identifies centripetal force as the only causality of gravitation raising valid questions regarding possibility for quantum gravitation.
\end{abstract}

Keywords: classical definitions, electricity, gravitation, magnetism, wave-particle duality

\section{Introduction}

We have been investigating the subject of how time interacts with space to define matter and have come to the conclusion that periodic (electrical) division of (magnetic) space produces the quantum atomic e-m radiation which then interacts with itself and its defining parameters to produce all of (visible and invisible) reality. The process is fully describable with the combined energy equations of Planck (1901) and Einstein (1905) within the context of de Broglie's (1923) interpretation. Using the combined equation it has been shown that the atom exists simultaneously as wave and as particle, Obande (2013). In other words, the expression $\mathrm{h} \vartheta=\mathrm{mc}^{2}$ simply

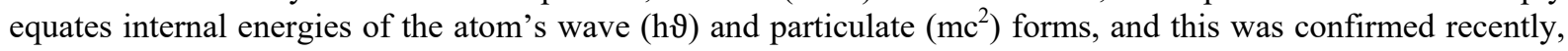
Obande (2015a, 2015b). Possibly, as a result of its primary connection with blackbody radiation, the frequency $\vartheta$ has all along been associated with one of several values obtainable from blackbody radiations or energy packets of an atom with the belief that no particular value specifically relates to the element's atomic mass. It turns out, however, that every element is uniquely defined with a specific $\vartheta$ value; but, absence of a theoretical basis for evaluating this value has constrained use of the equation for absolute atomic mass determination. We found by chance the $\vartheta$ values published long ago by Russell (1981) and following his excellent hints were able to produce the comprehensive list reported recently, Obande (2015a). In our opinion, the fact that Russell received no training in physics nor an allied branch of the sciences should not detract from the value of his publication provided his data passed requisite falsification tests. Our first test was to examine the possibility of reproducing established relative atomic mass $m_{r}$ from his $\vartheta$ values (Obande, 2013). This test turned out not merely successful, it produced interesting results capable of elucidating and broadening the base of theoretical physics. A clear distinction is made between absolute $\mathrm{m}_{\mathrm{abs}}\left(\right.$ or $\mathrm{m}_{\mathrm{w}}$ ) and relative $\mathrm{m}_{\mathrm{r}}$ atomic mass; the latter is shown to be a composite of the former with hydrogen atom playing the determinant for which reason it appears, although falsely so, as first element of the chemical periodicity. Next, we examined the subject of the atom's internal energy $E_{\text {int }}$. The results confirmed the earlier observation that the atom exists simultaneously as independent but 
interactive complementary wave and particulate forms, it also revealed that conversion of gross matter to energy succeeds only in destroying the particulate composite's (molar) fabric and releasing constituent single atoms in the waveform, Obande (2015a). These findings introduced a new dimension to the traditional notion of wave-particle duality; it is no longer a matter of the atom behaving at one instance as wave and as particle at another. We now find the atom existing simultaneously in two independent but complementary states as wave and as particle each defined by its specific wavelength. With these results it became obvious that the atom must be a simple harmonic e-m oscillator describable in all its ramifications with SHM formalisms. Results of SHM analysis of the e-m fields were presented in a preceding article Obande (2015b); here, we present results of comparing with some physical constants correlation coefficients of interaction of the atom's SHM parameters.

\section{Method}

In order to ease cross-referencing we reproduce from the preceding report relevant expressions upon which the present one hinges:

\begin{tabular}{|c|c|c|c|c|}
\hline Atomic radius, $r$ & $\lambda / 2$ & $=$ & $\mathrm{c} / 29$ & \\
\hline Density, $\quad \rho$ & $\mathrm{m} / \mathrm{v}$ & $=$ & $\mathrm{m} /\left(4 \pi \mathrm{r}^{3} / 3\right)$ & $=6 \mathrm{~m} \vartheta^{3} / \pi \mathrm{c}^{3}$ \\
\hline Angular speed, $\omega$ & $2 \pi \vartheta$ & & & \\
\hline Centripetal force, $\mathrm{F}$ & $=m \omega^{2} \mathrm{r}$ & $=$ & $8 \pi^{2} m \vartheta^{3} / \mathrm{c}$ & \\
\hline Young's modulus, $\epsilon$ & $=m \omega^{2}$ & $=$ & $4 \pi^{2} m \vartheta^{2}$ & \\
\hline Longitud. stress, $\sigma$ & $=\mathrm{F} / \pi \mathrm{r}^{2}$ & $=$ & $8 \pi \mathrm{m} \vartheta^{3} / \mathrm{c}$ & \\
\hline Strain, $\quad \tau$ & $\sigma / \epsilon$ & $=$ & $29 / \pi c$ & $=\omega / \pi^{2} \mathrm{c}$ \\
\hline
\end{tabular}

In order to correctly use these expressions it is important to remember that values of the parameters $\mathrm{m}, \mathrm{c}, \vartheta$ and $\lambda$ vary with the atom's form (wave or particle) and domain (micro- or macrocosm), see Obande (2015b).

For consistency, we evolve the following set of Rules for selecting the physical constant which best fits a particular coefficient: (i) Dimensional comparability - Dimensions of the two correlating parameters must not differ significantly and, at best, be identical with established dimensions of the candidate physical constant. (ii) Order of magnitude - Within reasonable limits, in addition to (i), the coefficient must be of the same order of magnitude as the candidate constant. (iii) Metric suitability - In some cases correctly matching the waveform parameter with the candidate constant may require conversion of all terms in the quantitative expression, including mass, to corresponding radiation equivalents. Thus, for correlations involving say waveform (i.e. vacuum) modulus $\epsilon_{\mathrm{w}}$ the quantity $\mathrm{m}$ in Equation (5) must be replaced with $\mathrm{h} 9 / \mathrm{c}^{2}$. If, on the other hand, modulus of the particulate atom $\epsilon_{\mathrm{p}}$ is required $\mathrm{m}$ is retained in $\mathrm{m} \omega^{2}$. (iv) Geometric orientation - In certain rare cases where the waveform coefficient would not match a candidate constant it may be necessary to replace $\vartheta$ with $\lambda$. In other cases where all effort to correlate fails but there is a compelling reason, say, on grounds of Rules (i) and (ii), to assign the coefficient to a given constant it is understood that Equations (1) to (7) represent first approximations only, it is likely that a perfect match would require trigonometric analysis and/or incorporation of some purely geometric factor. Results of these analyses are presented.

\section{Results}

The results are compiled in Tables 1 and 2. A total of ninety six correlations plus the inverse of each were examined; each is describable with one of the following conical sections: (i) $y=a x^{b}$ and $x=a y^{b}$, where $x y=k$, e.g., atomic mass $\mathrm{m}$ and radius $\mathrm{r}$; (ii) $\mathrm{y}=\mathrm{ax}$ and $\mathrm{x}=(1 / \mathrm{a}) \mathrm{y}^{\mathrm{b}}$, where $\mathrm{y} / \mathrm{x}=\mathrm{k}$, e.g., $\mathrm{m}$ and $\vartheta$; (iii) $\mathrm{y}=\mathrm{ax}^{\mathrm{b}}$ and $\mathrm{x}=$ $\mathrm{cy}^{1 / \mathrm{b}}$, where $|\mathrm{a}(1 / \mathrm{b})|=|\mathrm{bc}|$, i.e., product of one coefficient and exponent of the other and vice-versa have equal absolute values, this combines both hyperbolic and parabolic sections, e.g., atomic mass $\mathrm{m}$ and density $\rho$; the details are discussed.

\section{Discussion}

\subsection{Gravitation}

Correlations that yield coefficients indicative of $\mathrm{G}$ or $\mathrm{g}$ are examined.

\subsubsection{Newton's G}

Examples of correlations indicative of Newtonian gravitational constant G are presented in Equations (8) and (9), and illustrated in Figure 1 and 2.

$$
\begin{aligned}
& \mathrm{r}_{\mathrm{w}} \rho_{\mathrm{w}}^{0.25}=\mathrm{k}_{2}=2.29087 \times 10^{-11}(\mathrm{~kg} \mathrm{~m})^{0.25} \\
& \rho_{\mathrm{w}} / \epsilon_{\mathrm{w}}^{1.333}=\mathrm{k}_{3}=2.75423 \times 10^{-11} \mathrm{~m}^{-3} \mathrm{~s}^{2.666} \mathrm{~kg}^{-0.333}
\end{aligned}
$$


We ascribe $\mathrm{k}_{2}=2.29087 \times 10^{-11}(\mathrm{~kg} \mathrm{~m})^{0.25}$ to $\mathrm{G}$ on the basis of similarity of orders of magnitude (Rule (i)) and the fact that dimensionally, density is implicated in G's empirical definition. Equation (8) supports the fact that gravitational flux density decreases with distance from the body's centre of mass. The two equations, (8) and (9), reveal, perhaps surprisingly, that Newtonian gravitation is an atomic waveform (bosonic) phenomenon, particulate (fermionic) matter plays no role whatsoever; see Obande (2015b). CODATA (2014) gives $\mathrm{G}=$ $6.67408 \times 10^{-11} \mathrm{~m}^{3} \mathrm{~kg}^{-1} \mathrm{~s}^{-2}$; the constant $\mathrm{k}_{2}$ falls short of this empirical value by $0.937 \pi$, suggesting the possibility of an angular contribution accessible, perhaps, only with trigonometric analysis. Dimensional analysis gives $\mathrm{k}_{2}=$ $\left(3 \mathrm{~m}_{\mathrm{w}} \mathrm{r}_{\mathrm{w}} / 4 \pi\right)^{0.25}=2.6698876353 \times 10^{-11}(\mathrm{~kg} \mathrm{~m})^{0.25}$ a value consistent with the graphical extrapolation (note: for, say, the electron waveform $\mathrm{m}_{\mathrm{e}(\mathrm{w})}=7.37 \times 10^{-51} \mathrm{~kg}$ and $\mathrm{r}_{\mathrm{e}(\mathrm{w})}=1.4990 \times 10^{8} \mathrm{~m}$ (Obande, 2015b)). Based therefore on order of magnitude and suitability of interacting parameters, the quantity $0.937 \pi \mathrm{k}_{2}=6.67435 \times 10^{-11}(\mathrm{~kg}$ $\mathrm{m})^{0.25}$ is attributable to Newtonian gravitation.

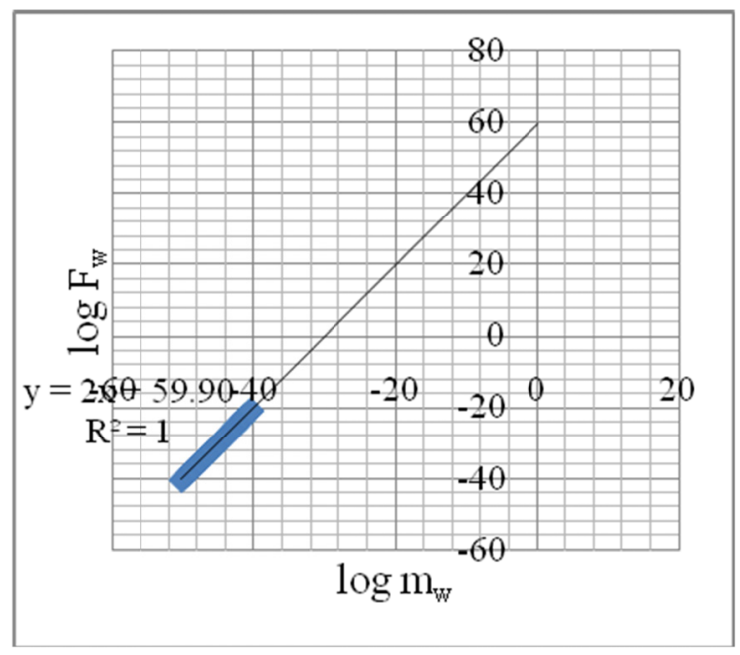

Figure 1. Plot of $\log \mathrm{F}_{\mathrm{w}}$ vs. $\log \mathrm{m}_{\mathrm{w}}-$ wave

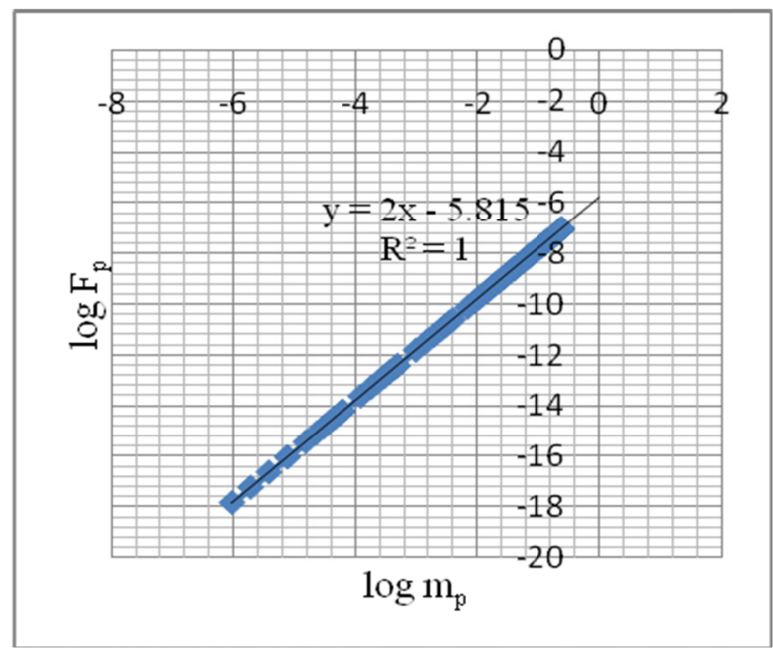

Figure 3. Plot of $\log \mathrm{F}_{\mathrm{p}}$ vs. $\mathrm{m}_{\mathrm{p}}$ - particle

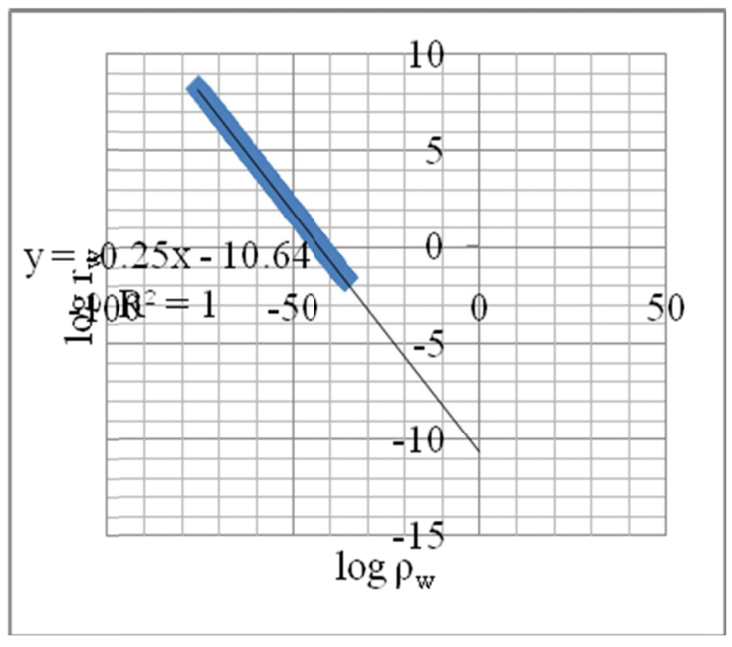

Figure 2. Plot of $\log r_{w}$ vs. $\log \boldsymbol{\rho}_{w}-$ wave

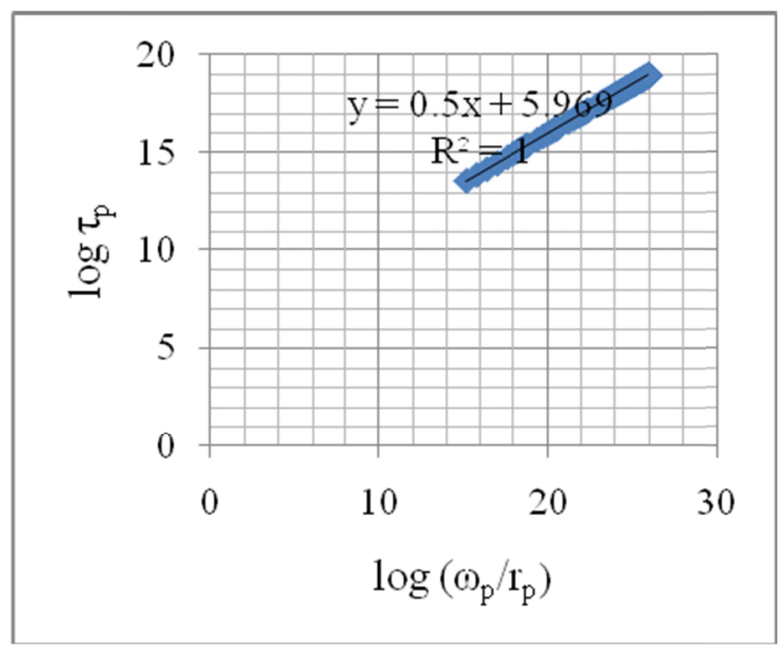

Figure 4. Plot of $\log \tau_{\mathrm{p}}$ vs. $\log \left(\omega / \mathrm{r}_{\mathrm{p}}\right)-$ particle

The constant $\mathrm{k}_{3}$ suggests that gravitational flux density $\rho_{\mathrm{w}}$ increases with an increase in waveform modulus; it meets Rule (ii) but the unit is not only inverse empirical G, it presents with fractional exponents of mass and time. Interestingly, these are the same powers to which $\vartheta$ value of an element must be raised to get $\vartheta$ value of the next element. In other words, we are presented with an internal consistency that might unfold only with full development of the relevant theoretical framework. The quantity $\rho / \epsilon$ contains the essential dimensions mass, length, and time and these combine to give $\mathrm{k}_{3}=\mathrm{b} /\left(\mathrm{m}^{0.333} \mathrm{r}^{3} \vartheta^{2.666}\right)$. Substituting for $\mathrm{b}=3 /\left(4^{2.333} \pi^{3.666}\right), \mathrm{m}_{\mathrm{e}(\mathrm{w})}=$ 
$7.3725 \times 10^{-51} \mathrm{~kg}, \mathrm{r}_{\mathrm{e}(\mathrm{w})}=1.4490 \times 10^{8} \mathrm{~m}$, and $\vartheta_{\mathrm{e}(\mathrm{w})}=1.0 \mathrm{~Hz}$, we get $\mathrm{k}_{3}=2.60416 \times 10^{-11} \mathrm{~m}^{-3} \mathrm{~s}^{2.666} \mathrm{~kg}^{-0.333}$ which

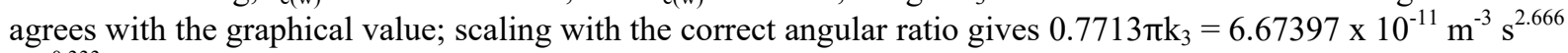
$\mathrm{kg}^{-0.333}$ well in line with empirical $\mathrm{G}$ value suggesting again the possibility of a geometric factor.

\subsubsection{Galileo's g}

The universal unit of (gravitational) acceleration, Galileo or gal, is $g=1.0 \times 10^{-6} \mathrm{~m} \mathrm{~s}^{-2}$, Emiliani (1995). It turned out, e.g., Figure 1 and 3, that the following coefficients are relevant:

$$
\begin{aligned}
& \mathrm{F}_{\mathrm{w}} / \mathrm{m}_{\mathrm{w}}^{2}=\mathrm{k}_{1}=7.94328 \times 10^{59} \mathrm{~m} \mathrm{~s}^{-2} \mathrm{~kg}^{-1} \\
& \mathrm{~F}_{\mathrm{p}} / \mathrm{m}_{\mathrm{p}}{ }^{2}=\mathrm{k}_{\mathrm{a}}=1.531087 \times 10^{-6} \mathrm{~m} \mathrm{~s}^{-2} \mathrm{~kg}^{-1} \\
& \mathrm{r}_{\mathrm{p}} \rho_{\mathrm{p}}^{0.25}=\mathrm{k}_{\mathrm{b}}=6.79204 \times 10^{-6}(\mathrm{~kg} \mathrm{~m})^{0.25} \\
& \epsilon_{\mathrm{w}} / \sigma^{0.75}=\mathrm{k}_{\mathrm{w}}=2.34963 \times 10^{-6}(\mathrm{~kg} \mathrm{~m})^{0.25} \mathrm{~s}^{-1}
\end{aligned}
$$

Equations (10) and (11) are identical, both refer to the same phenomenon, $\mathrm{k}_{1}$ applies to the waveform while $\mathrm{k}_{\mathrm{a}}$ applies to particulate matter. The waveform invariant gravitational (centripetal) acceleration $\mathrm{k}_{1}=7.9433 \times 10^{59}$ $\mathrm{m} \mathrm{s}^{-2} \mathrm{~kg}^{-1}$ would suggest that every particulate (fermionic) matter, from the atom to the galaxy, is enclosed within its corresponding waveform (bosonic field) envelope. We had to evoke this same universal "plum-pudding model" to account for radioactivity and also in analysis of relevant distinctions between speed and velocity of light, Obande (2015b; 2015c); given the model, $\mathrm{k}_{1}$ interprets as an invariant waveform gravitational acceleration holding matter together on all scales from the atom to the cosmos. We reason that $\mathrm{k}_{1}$ is indicative of the "strong nuclear force" (SNF). In other words, the atomic nucleus is not held together by electromagnetic but by an incredible mechanical force of gravitational (centripetal) acceleration per unit mass. Inordinately high energy requirement to split the atom would support this position. Notably, $\mathrm{k}_{1}$ is an atomic bosonic (waveform) property in line with Standard Model's description of the boson as force carrier. For particulate matter, however, $\mathrm{k}_{\mathrm{a}}=$ $1.531087 \times 10^{-6} \mathrm{~m} \mathrm{~s}^{-2} \mathrm{~kg}^{-1}$ revealing that it binds with an insignificant $\mathrm{g}$ value and therefore is held in place by centripetal force of its corresponding bosonic wave form envelope. This is as well since the intrinsic weak force allows particulate matter to exist in isolation and be alterable with relatively little force. Observe that Equations (1) to (13) present a new and very fascinating picture of the classical mechanical, non electromagnetic, forces holding matter together on scales varying from the atom to the cosmos. Briefly, it is revealed that reality is held in place by forces of rotational motion, i.e., spin only; electromagnetic forces would seem to become relevant mainly to effect chemical bonding.

The results summarized in Equations (8) and (12) for wave and particulate matter respectively would suggest that gravitation could not possibly be due to e-m interaction as originally presumed by Lorentz (1900) and his predecessors and developed into its present form by Einstein (1950); it is shown here to result from coupling of centripetal (mechanical) force fields of wave (bosonic) forms of two interacting bodies. Indeed, we should expect no possibility for discernible quantum gravitation within the cosmic envelope for two main reasons: Firstly, a quantum phenomenon is discernible only outside its envelope (see for instance the quantum photon envelope captured with the brilliant innovation of the Washington University team (Gao, 2014), G is measured within its envelope $\left(\mathrm{r}_{\mathrm{e}(\mathrm{w})}=1.499 \times 10^{8} \mathrm{~m}\right)$. Secondly, quantum gravitation, if it existed, would be a ceaseless pulsating exchange of discrete packets; on galactic scale, this could spell disaster for the entire cosmic structural framework presumably similar to the effect of harmonic oscillation on inadequately secured structural members. Gravitation happens to be the structural member securing the entire cosmic framework. Attempts to develop a viable quantum gravitation theory date back to pioneers of modern physics, Renn (2007), but as evident from his excellent review and contributions, the subject seems to remain to date where Lorentz (1900) left it, inconclusive.

\subsection{Electricity}

\subsubsection{Electric Potential Atomic Mass Unit, amu/eV}

The CODATA (2014) recommendation gives $\mathrm{amu}=931.4940954 \mathrm{MeV}$ and we find in Figure 4 that the particulate atom's rotational strain rate $\tau_{\mathrm{p}}$ correlates with its angular speed per unit radius $\omega_{\mathrm{p}} / \mathrm{r}_{\mathrm{p}}$ to give:

$$
\tau_{\mathrm{p}} \quad=\mathrm{k}_{4}\left(\omega_{\mathrm{p}} / \mathrm{r}_{\mathrm{p}}\right)^{0.5} \mathrm{rad}^{0.5} \mathrm{~m}^{-0.5} \mathrm{~s}^{-0.5}
$$

where the correlation coefficient $\mathrm{k}_{4}=931.1078755 \times 10^{5}$ agrees reasonably with the CODATA value. This singular result stands out as the strongest undisputable proof yet of validity of the reported $\vartheta$ values (Obande, 2015a) and our falsification procedures. Notably: (i) $\tau$ 's unit is reminiscent of spin quantum number $m_{s}= \pm 1 / 2$, here it identifies with the unit $\pm\left(\mathrm{rad} \mathrm{s}^{-1} \mathrm{~m}^{-1}\right)^{1 / 2}$; (ii) Equation (14) is in line with Macken's (2011) submission that "An electric field is ... an unsymmetrical distortion of space-time"; asymmetrical distortion appears in Equation 
(14) as strain, interpretable as de Broglie's (1923) inertia or Lorentz's (1952) 'back reaction' noted recently by Wilczek (2012) as the major contributor to atomic mass. Thus, we have in Equation (14) a unique physical interpretation of inertial mass in terms of quantum angular speed per unit radius of the defining transverse e-m field. Indeed, in order to arrive at his energy equation Planck (1901) did make the same assumption underlying this investigation, namely, matter must be a collection of discrete harmonic oscillators that obeyed energy-frequency law of the form $\mathrm{E}=\mathrm{h} \vartheta$.

4.2.2 Electric Constant (Permittivity) $\varepsilon$ and Electron Compton Wavelength $\lambda_{\mathrm{c}}$

Correlations that relate to $\varepsilon$ and $\lambda_{c}$ are illustrated in Figure 5 and 6 and in rows 4 to 8 , Table 1; they are defined as follows:

$$
\begin{array}{lll}
\epsilon_{\mathrm{p}} / \sigma_{\mathrm{p}}{ }^{0.75}= & \mathrm{k}_{\mathrm{e}}=7.943282347 \times 10^{-12} \\
\mathrm{r}_{\mathrm{p}} \sigma_{\mathrm{p}}{ }^{0.25}= & \mathrm{k}_{\mathrm{f}}=2.511886432 \times 10^{-12}
\end{array}
$$

Values of $\mathrm{k}_{\mathrm{e}}$ and $\mathrm{k}_{\mathrm{f}}$ compare well with CODATA $\epsilon=8.85418782 \times 10^{-12} \mathrm{~F} \mathrm{~m}^{-1}$ and electron $\lambda_{\mathrm{c}}=2.4263102367 \mathrm{x}$ $10^{-12} \mathrm{~m}$ respectively. Dimensional analyses give $\mathrm{k}_{\mathrm{e}}=\pi^{0.75} \mathrm{~m}_{\mathrm{p}}^{0.25} \omega_{\mathrm{p}}^{0.5} \mathrm{r}_{\mathrm{p}}^{0.75}$, and $\mathrm{k}_{\mathrm{f}}=\pi^{-0.5} \mathrm{~m}_{\mathrm{p}}^{0.25} \omega_{\mathrm{p}}^{0.5} \mathrm{r}_{\mathrm{p}}^{0.75}$; substitution of values of these parameters gives $\mathrm{k}_{\mathrm{e}}=7.835589174 \times 10^{-12} \mathrm{~m}_{\mathrm{p}}^{0.25} \omega_{\mathrm{p}}^{0.5} \mathrm{r}_{\mathrm{p}}^{0.75}$ and $\mathrm{k}_{\mathrm{f}}=2.46299979 \mathrm{x}$ $10^{-12} \mathrm{~m}_{\mathrm{p}}^{0.25} \omega_{\mathrm{p}}^{0.5} \mathrm{r}_{\mathrm{p}}^{0.75}$ which agree remarkably with the graphical values of Equations (15) and (16). Notably, the difference between $k_{\mathrm{e}}$ and $\mathrm{k}_{\mathrm{f}}$ is geometric appearing respectively as $\pi^{0.75}$ and $\pi^{-0.5}$. In other words, $\epsilon$ and $\lambda_{\mathrm{c}}$ are both essentially functions of the atom's angular momentum $\left(\mathrm{m}_{\mathrm{p}} \mathrm{r}_{\mathrm{p}} \omega_{\mathrm{p}}\right)^{0.25} \mathrm{r}_{\mathrm{p}}{ }^{0.5}$. This and several similar results would suggest that geometric orientation contributes significantly to the gravitational, electrical or magnetic outcome of a given parametric interaction.

\subsection{Magnetism}

\subsubsection{Electron Magnetic Moment $\mu_{\mathrm{e}}$}

The recommended value of electron magnetic moment is $\mu_{\mathrm{e}}=9.284764620 \times 10^{-24} \mathrm{~J} \mathrm{~T}^{-1}$, the correlation that best fits this definition is illustrated in Figure 7 and expressible as

$$
\mathrm{F}_{\mathrm{w}} / \tau_{\mathrm{w}}{ }^{2}=\mathrm{k}_{9}=9.772372210 \times 10^{-24}
$$

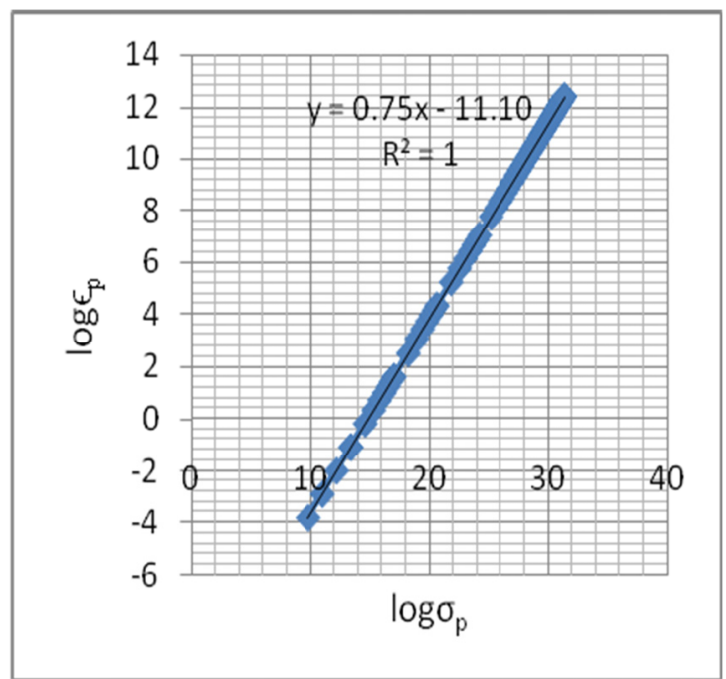

Figure 5. Plot of $\log \epsilon_{\mathrm{p}}$ vs. $\log \sigma_{\mathrm{p}}$ - particle

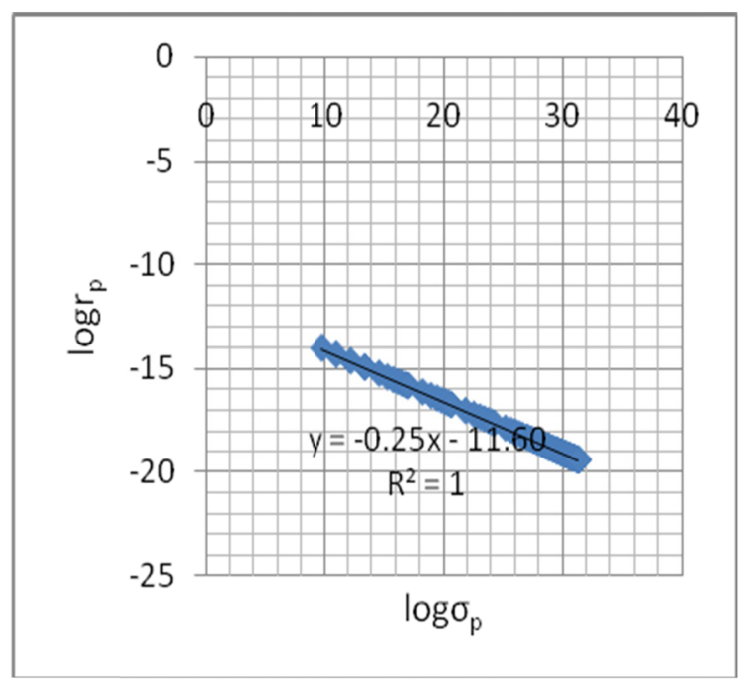

Figure 6. Plot of $\log r_{p}$ vs. $\log \sigma_{p}$ - particle

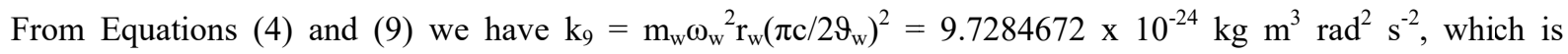
remarkably close to the graphical and recommended values of $\mu_{\mathrm{e}}$; furthermore, the parametric equivalence of the unit $\mathrm{J} \mathrm{T}^{-1}$ turns out as $\mathrm{kg} \mathrm{m}^{3}\left(\mathrm{rad} \mathrm{s}^{-1}\right)^{2}$. Notably, it is revealed that $\mu_{\mathrm{e}}$ refers to the electron wave $\left(\mathrm{e}_{\mathrm{w}}\right)$ and not particulate $\left(\mathrm{e}_{\mathrm{p}}\right)$ form. Observe in Equations (17), (10) and (11) that centripetal force $\mathrm{F}$ is the independent variable in parametric interactions that give rise to gravitational acceleration and magnetism; F interacts with mass in gravitational acceleration and with the waveform's rotational strain $\tau$ in magnetism. 
Table 1. Comparison of coeffs. of parametric equations with some physical constants

\begin{tabular}{|c|c|c|c|c|c|c|}
\hline $\mathrm{S} /$ & Parametric & & Physical & Parametric & & Physical \\
\hline No. & Equation & Coefficient & Constant & Equation & Coefficient & Constant \\
\hline \multicolumn{7}{|c|}{ Gravitational constants } \\
\hline 1 & $\mathrm{~F}_{\mathrm{w}}=\mathrm{k}_{1} \mathrm{~m}^{2}$ & $\mathrm{k}_{1}=7.943 \mathrm{E} 59$ & Unkown & $\mathrm{F}_{\mathrm{p}}=\mathrm{k}_{\mathrm{a}} \mathrm{m}^{2}$ & $\mathrm{k}_{\mathrm{a}}=1.531 \mathrm{E}-6$ & $\mathrm{gal}=1 \mathrm{E}-6 \mathrm{~m} \cdot \mathrm{s}_{-}^{2}$ \\
\hline 2 & $\mathrm{r}_{\mathrm{w}}=\mathrm{k}_{2} \rho^{-0.25}$ & $\mathrm{k}_{2}=2.291 \mathrm{E}-11$ & $\mathrm{G}=6.674 \mathrm{E}-11$ & $\mathrm{r}_{\mathrm{p}}=\mathrm{k}_{\mathrm{b}} \rho^{-0.25}$ & $\mathrm{k}_{\mathrm{b}}=6.792 \mathrm{E}-6$ & $\mathrm{gal}=1 \mathrm{E}-6 \mathrm{~m} \cdot \mathrm{s}^{-2}$ \\
\hline 3 & $\rho_{\mathrm{w}}=\mathrm{k}_{3} \mathrm{\epsilon}^{1.333}$ & $\mathrm{k}_{3}=2.754 \mathrm{E}-11$ & $\mathrm{G}=6.674 \mathrm{E}-11$ & $\epsilon_{\mathrm{w}}=\mathrm{k}_{\mathrm{c}} \sigma^{0.75}$ & $\mathrm{k}_{\mathrm{c}}=2.3496 \mathrm{E}-6$ & $\mathrm{gal}=1 \mathrm{E}-6 \mathrm{~m} \cdot \mathrm{s}^{-2}$ \\
\hline \multicolumn{7}{|c|}{ Electrical Constants } \\
\hline 4 & $\tau_{\mathrm{w}}=\mathrm{k}_{4}(\omega / \mathrm{r})^{0.5}$ & $\mathrm{k}_{4}=1.038 \mathrm{E}-5$ & $\mathrm{e}-\mathrm{amu}=1.038 \mathrm{E}-5$ & $\tau_{\mathrm{p}}=\mathrm{k}_{\mathrm{d}}(\omega / \mathrm{r})^{0.5}$ & $\mathrm{k}_{\mathrm{d}}=9.31108 \mathrm{E} 5$ & $\mathrm{amu}=931.494 \mathrm{MeV}$ \\
\hline 5 & $\vartheta_{\mathrm{w}}=\mathrm{k}_{5} \rho^{0.25}$ & $\mathrm{k}_{5}=6.607 \mathrm{E} 18$ & $\mathrm{C}=6.2415 \mathrm{E} 18 \mathrm{e}$ & $\epsilon_{\mathrm{p}}=\mathrm{k}_{\mathrm{e}} \sigma^{0.75}$ & $\mathrm{k}_{\mathrm{e}}=7.943 \mathrm{E}-12$ & $\epsilon_{\mathrm{o}}=8.854 \mathrm{E}-12 \mathrm{~F} / \mathrm{m}$ \\
\hline 6 & $\vartheta_{\mathrm{w}}=\mathrm{k}_{6} \tau$ & $\mathrm{k}_{6}=4.699 \mathrm{E} 8$ & $1.5674 \mathrm{c}=4.699 \mathrm{E} 8$ & $\mathrm{r}_{\mathrm{p}}=\mathrm{k}_{\mathrm{f}} \sigma^{-0.25}$ & $\mathrm{k}_{\mathrm{f}}=2.5119 \mathrm{E}-12$ & $\lambda_{\mathrm{c}}=2.426 \mathrm{E}-12 \mathrm{~m}$ \\
\hline 7 & $\vartheta_{\mathrm{p}}=\mathrm{k}_{7} \sigma^{4}$ & $\mathrm{k}_{7}=3.243 \mathrm{E} 8$ & StatAmp $=2.998 \mathrm{E} 8$ & $\rho_{\mathrm{p}}=\mathrm{k}_{\mathrm{g}} \tau^{4}$ & $\mathrm{k}_{\mathrm{g}}=2.089 \mathrm{E}-19$ & $\mathrm{amu}=1.602 \mathrm{E}-19 \mathrm{C}$ \\
\hline 8 & $\epsilon_{\mathrm{w}}=\mathrm{k}_{8} \mathrm{~F}^{0.5}$ & $\mathrm{k}_{8}=1.00 \mathrm{E} 12$ & Charge-amu $=1.081 \mathrm{E} 12$ & $\omega_{\mathrm{p}}=\mathrm{k}_{\mathrm{h}} \epsilon^{0.333}$ & $\mathrm{k}_{\mathrm{h}}=2.355 \mathrm{E} 2$ & $Z_{o}=3.767 \mathrm{E} 2 \Omega$ \\
\hline \multicolumn{7}{|c|}{ Magnetic constants } \\
\hline 9 & $\mathrm{~F}_{\mathrm{w}}=\mathrm{k}_{9} \tau^{2}$ & $\mathrm{k}_{9}=9.772 \mathrm{E}-24$ & $\mu_{\mathrm{e}}=9.285 \mathrm{E}-24 \mathrm{~J} / \mathrm{T}$ & $\sigma_{\mathrm{p}}=\mathrm{k}_{\mathrm{i}} \rho$ & $\mathrm{k}_{\mathrm{i}}=1.820 \mathrm{E}-26$ & $\mu_{\mathrm{p}}=1.141 \mathrm{E}-26 \mathrm{~J} / \mathrm{T}$ \\
\hline 10 & $\rho_{\mathrm{w}}=\mathrm{k}_{10} \mathrm{~F}^{2}$ & $\mathrm{k}_{10}=2.742 \mathrm{E} 5$ & $\mathrm{~B}-\mathrm{amu}=2.351 \mathrm{E} 5 \mathrm{Tes} l \mathrm{a}$ & $\mathrm{m}_{\mathrm{p}}=\mathrm{k}_{\mathrm{j}} \epsilon^{0.333}$ & $\mathrm{k}_{\mathrm{j}}=1.803 \mathrm{E}-5$ & $\mu_{\mathrm{B}}=5.788 \mathrm{E}-5 \mathrm{eV} / \mathrm{T}$ \\
\hline 11 & $\mathrm{~m}_{\mathrm{p}}=\mathrm{k}_{11} \rho^{0.25}$ & $\mathrm{k}_{11}=1.318 \mathrm{E}-15$ & Flux $=2.068 \mathrm{E}-15 \mathrm{~Wb}$ & $\mathrm{rp}=\mathrm{kk \sigma}-0.25$ & $\mathrm{k}_{\mathrm{k}}=7.482 \mathrm{E}-7$ & $\mu_{\mathrm{o}}=12.566 \mathrm{E}-7 \mathrm{~N} / \mathrm{A}^{2}$ \\
\hline \multicolumn{7}{|c|}{ Electron mass } \\
\hline 12 & $\mathrm{~m}_{\mathrm{w}}=\mathrm{k}_{12} \mathrm{\vartheta}$ & $\mathrm{k}_{12}=7.413 \mathrm{E}-51$ & $\mathrm{~m}_{\mathrm{e}}=9.109 \mathrm{E}-31$ & $\mathrm{~m}_{\mathrm{p}}=\mathrm{k}_{\mathrm{l}} \vartheta$ & $\mathrm{k}_{\mathrm{l}}=4.887 \mathrm{E}-7$ & $\mathrm{~m}_{\mathrm{e}}=5.11 \mathrm{E}-7 \mathrm{~kg}$ \\
\hline \multicolumn{7}{|c|}{ Some other correlation coefficients } \\
\hline 13 & $\mathrm{~T}_{\mathrm{p}}=\mathrm{k}_{13} \omega$ & $\mathrm{k}_{13}=2.6915 \mathrm{E} 12$ & - & $\rho_{\mathrm{p}}=\mathrm{k}_{\mathrm{m}} \mathrm{m}^{4}$ & $\mathrm{~km}=3.311 \mathrm{E} 59$ & \multirow[b]{2}{*}{$\mathrm{amu}=8.239 \mathrm{E}-8 \mathrm{~N}$} \\
\hline 14 & $\mathrm{~F}_{\mathrm{w}}=\mathrm{k}_{14} \sigma^{0.25}$ & $\mathrm{~K}_{14}=1.778 \mathrm{E}-12$ & - & $\mathrm{m}_{\mathrm{p}}=\mathrm{k}_{\mathrm{n}} \omega$ & $\mathrm{k}_{\mathrm{n}}=7.656 \mathrm{E}-8$ & \\
\hline 15 & $\sigma_{\mathrm{p}}=\mathrm{k}_{15} \vartheta^{0.25}$ & $\mathrm{k}_{15}=7.465 \mathrm{E}-3$ & $\alpha=7.297 \mathrm{E}-3$ & $\omega_{\mathrm{p}}=\mathrm{k}_{0} \mathrm{~F}^{0.25}$ & $\mathrm{k}_{\mathrm{o}}=1.047 \mathrm{E} 10$ & - \\
\hline 16 & $\tau_{\mathrm{p}}=\mathrm{k}_{16} \mathrm{r}^{-1}$ & $\mathrm{k}_{16}=0.3184$ & $1 / \pi=0.3183$ & $\mathrm{~m}_{\mathrm{p}}=\mathrm{k}_{\mathrm{p}} \tau$ & $\mathrm{k}_{\mathrm{p}}=3.548 \mathrm{E} 19$ & - \\
\hline 17 & $\vartheta_{\mathrm{w}}=\mathrm{k}_{17} \mathrm{r}^{-1}$ & $\mathrm{k}_{17}=1.496 \mathrm{E} 8$ & $\mathrm{c} / 2=1.499 \mathrm{E} 8 \mathrm{~m} / \mathrm{s}$ & $\tau \mathrm{p}=\mathrm{k}_{\mathrm{p}} \mathrm{m}$ & $\mathrm{k}_{\mathrm{p}}=3.548 \mathrm{E} 19$ & - \\
\hline 18 & $\omega_{\mathrm{p}}=\mathrm{k}_{18} \vartheta^{-1}$ & $\mathrm{k}_{18}=6.2806$ & $2 \pi=6.2832$ & $\vartheta_{\mathrm{p}}=\mathrm{k}_{\mathrm{q}} \mathrm{r}^{-1}$ & $\mathrm{k}_{\mathrm{q}}=1.862 \mathrm{E}-14$ & - \\
\hline 19 & $\mathrm{r}_{\mathrm{w}}=\mathrm{k}_{19} \omega^{-1}$ & $\mathrm{k}_{19}=9.419 \mathrm{E} 8$ & $\pi \mathrm{c}=9.4183 \mathrm{E} 8 \mathrm{~m} / \mathrm{s}$ & $\mathrm{r}_{\mathrm{p}}=\mathrm{k}_{\mathrm{q}} \vartheta^{-1}$ & $\mathrm{k}_{\mathrm{q}}=1.862 \mathrm{E}-14$ & - \\
\hline 20 & $\mathrm{~m}_{\mathrm{w}}=\mathrm{k}_{20} \epsilon^{0.333}$ & $\mathrm{~K}_{20}=1.122 \mathrm{E}-34$ & $\mathrm{amu}=1.055 \mathrm{E}-34 \mathrm{~J} . \mathrm{s}$ & $\vartheta_{\mathrm{p}}=\mathrm{k}_{\mathrm{r}} \epsilon^{0.666}$ & $\mathrm{k}_{\mathrm{r}}=5.012 \mathrm{E}-16$ & $\mathrm{amu}=6.582 \mathrm{E}-16 \mathrm{eVs}$ \\
\hline 21 & $\vartheta_{\mathrm{w}}=\mathrm{k}_{21} \in 0^{.333}$ & $\mathrm{~K}_{21}=1.479 \mathrm{E} 16$ & - & $\mathrm{r}_{\mathrm{p}}=\mathrm{k}_{\mathrm{r}} \epsilon^{-0.333}$ & $\mathrm{k}_{\mathrm{r}}=5.012 \mathrm{E}-16$ & - \\
\hline 22 & $\tau_{\mathrm{p}}=\mathrm{k}_{22} \mathrm{~V} \vartheta$ & $\mathrm{k}_{22}=1.698 \mathrm{E} 13$ & - & $\mathrm{r}_{\mathrm{p}}=\mathrm{k}_{\mathrm{s}} \omega^{-1}$ & $\mathrm{k}_{\mathrm{s}}=1.175 \mathrm{E}-13$ & - \\
\hline 23 & $\omega_{\mathrm{w}}=\mathrm{k}_{23} \rho^{0.25}$ & $\mathrm{k}_{23}=4.074 \mathrm{E} 19$ & - & $\mathrm{F}_{\mathrm{p}}=\mathrm{k}_{\mathrm{t}} \vartheta^{2}$ & $\mathrm{k}_{\mathrm{t}}=3.548 \mathrm{E}-19$ & - \\
\hline 24 & $\mathrm{~F}_{\mathrm{p}}=\mathrm{k}_{24} \omega^{2}$ & $\mathrm{k}_{24}=8.913 \mathrm{E}-21$ & - & $\vartheta_{\mathrm{p}}=\mathrm{k}_{\mathrm{u}} \mathrm{F}^{0.5}$ & $\mathrm{k}_{\mathrm{u}}=1.683 \mathrm{E} 9$ & - \\
\hline 25 & $\epsilon_{\mathrm{w}}=\mathrm{k}_{25} \tau^{3}$ & $\mathrm{k}_{25}=3.09 \mathrm{E}-23$ & - & $\sigma_{\mathrm{w}}=\mathrm{k}_{\mathrm{v}} \mathrm{F}^{2}$ & $\mathrm{k}_{\mathrm{v}}=3.236 \mathrm{E} 23$ & - \\
\hline 26 & $\omega_{\mathrm{w}}=\mathrm{k}_{26} \epsilon^{0.333}$ & $\mathrm{k}_{26}=1.803 \mathrm{E}-5$ & - & $\tau_{\mathrm{w}}=\mathrm{k}_{\mathrm{w}} \sigma^{0.25}$ & $\mathrm{k}_{\mathrm{w}}=4.256 \mathrm{E} 5$ & - \\
\hline 27 & $\mathrm{r}_{\mathrm{w}}=\mathrm{k}_{27} \mathrm{Fw}^{-0.5}$ & $\mathrm{k}_{27}=1.0 \mathrm{E}-12$ & - & $\tau_{\mathrm{p}}=\mathrm{k}_{\mathrm{x}} \omega$ & $\mathrm{k}_{\mathrm{x}}=2.692 \mathrm{E} 12$ & - \\
\hline 28 & $\mathrm{~F}_{\mathrm{w}}=\mathrm{k}_{28} \mathrm{r}^{-2}$ & $\mathrm{k}_{28}=1.0 \mathrm{E}-24$ & - & $\omega_{\mathrm{p}}=\mathrm{k}_{\mathrm{y}} \tau$ & $\mathrm{k}_{\mathrm{y}}=3.7153 \mathrm{E}-13$ & $\mathrm{c}^{\mathrm{o}} / 10=3.715 \mathrm{E}-13 \mathrm{~m} / \mathrm{s}$ \\
\hline 29 & $\tau_{\mathrm{w}}=\mathrm{k}_{29} \rho$ & $\mathrm{k}_{29}=3.381 \mathrm{E}-10$ & - & $\tau_{\mathrm{p}}=\mathrm{k}_{\mathrm{z}} \rho^{0.25}$ & $\mathrm{k}_{\mathrm{z}}=4.774 \mathrm{E} 4$ & - \\
\hline 30 & $\tau_{\mathrm{w}}=\mathrm{k}_{30} \mathrm{~F}^{0.25}$ & $\mathrm{k} 2_{30}=3.162 \mathrm{E} 11$ & - & $\tau_{\mathrm{p}}=\mathrm{k}_{\mathrm{aa}} \mathrm{F}^{0.25}$ & $\mathrm{k}_{\mathrm{aa}}=2.884 \mathrm{E} 22$ & - \\
\hline 31 & $\tau_{\mathrm{w}}=\mathrm{k}_{31} \epsilon^{0.333}$ & $\mathrm{~K}_{31}=3.199 \mathrm{E} 7$ & - & $\tau_{\mathrm{p}}=\mathrm{k}_{\mathrm{ab}} \epsilon^{0.333}$ & $\mathrm{k}_{\mathrm{ab}}=6.310 \mathrm{E} 14$ & - \\
\hline
\end{tabular}

\subsubsection{Atomic Mass Unit of Magnetic Flux Density B}

The recommended value is $\mathrm{B}-\mathrm{amu}=2.350517464 \times 10^{5} \mathrm{~T}$; correlation of $\rho_{\mathrm{w}}$ with $\mathrm{F}_{\mathrm{w}}$ (Figure 8) gives, 


$$
\rho_{\mathrm{w}} / \mathrm{F}_{\mathrm{w}}{ }^{2}=\mathrm{k}_{10}=2.741574172 \times 10^{5}
$$

$B$ is a waveform parameter for which substitutions from Equations (2) and (4) give $\mathrm{k}_{10}=3 /\left(4 \pi \mathrm{r}^{5} \mathrm{~m}_{\mathrm{w}} \omega_{\mathrm{w}}{ }^{4}\right)=2.7300$ $\mathrm{x} 10^{5} \mathrm{~kg}^{-1} \mathrm{~m}^{-5}\left(\mathrm{rad} \mathrm{s}^{-1}\right)^{-4}$ which agrees well with the graphical and recommended values; the parameters combine to define the Tesla $(\mathrm{amu})$ in dimensions of $\left(\mathrm{kg} \mathrm{m}^{-1}\left(\mathrm{rad} \mathrm{s}^{-1} \mathrm{~m}^{-1}\right)^{-4}\right.$.

\subsubsection{Magnetic Flux Density B}

The CODATA value is $B=2.067833831 \times 10^{-15} \mathrm{~Wb}$, a log-log plot of $m_{p}$ vs. $\rho_{p}$ (Figure 9) gives the following correlation:

$$
\mathrm{m}_{\mathrm{p}} / \rho_{\mathrm{p}}^{0.25}=\mathrm{k}_{11}=1.318256739 \times 10^{-15}(\mathrm{~kg} \mathrm{~m})^{0.75}
$$

This is a particulate matter parameter for which substitution from Equation (2), noting that for, say, the electron, $\mathrm{m}_{\mathrm{p}(\mathrm{e})}=4.8828 \times 10^{-7} \mathrm{~kg}$ and $\mathrm{r}_{\mathrm{p}(\mathrm{e})}=1.8262 \times 10^{-14} \mathrm{~m}$ (Table 2), gives $\mathrm{k}_{11}=(4 \pi / 3)^{0.25}\left(\mathrm{~m}_{\mathrm{p}} \mathrm{r}_{\mathrm{p}}\right)^{0.75}=1.313502603 \mathrm{x}$ $10^{-15}(\mathrm{~kg} \mathrm{~m})^{0.75}$ in excellent agreement with the graphical value; multiplication of $\mathrm{k}_{11}$ by $0.4993 \pi$ gives the CODATA value. The unit $(\mathrm{kg} \mathrm{m})^{0.75}$ implies that the Weber is a measure of work done to move unit mass a unit distance; observe that Equations (8) and (19) are consistent with the fact that magnetism and gravitation function alike - they both exert inward pull. Furthermore, Equation (8) is perfectly in line with the fact that G's flux density is inversely related to distance, while Equation (19) shows that B's flux density is directly proportional to mass of the body. It is hoped that a theoretical framework would throw more light on the exact profiles of the gravitational, electrical and magnetic force fields.

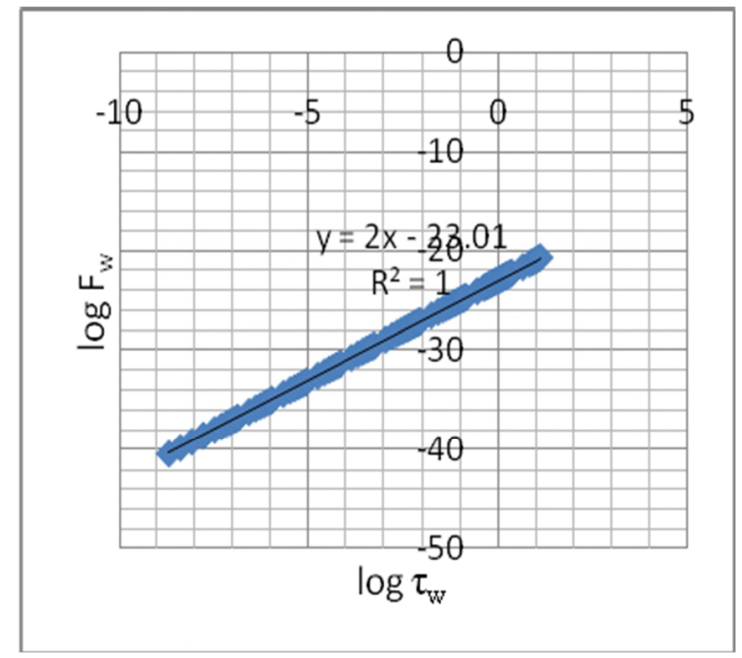

Figure 7. Plot of $\log \mathrm{F}_{\mathrm{w}}$ vs. $\log \boldsymbol{\tau}_{\mathrm{w}}-$ wave

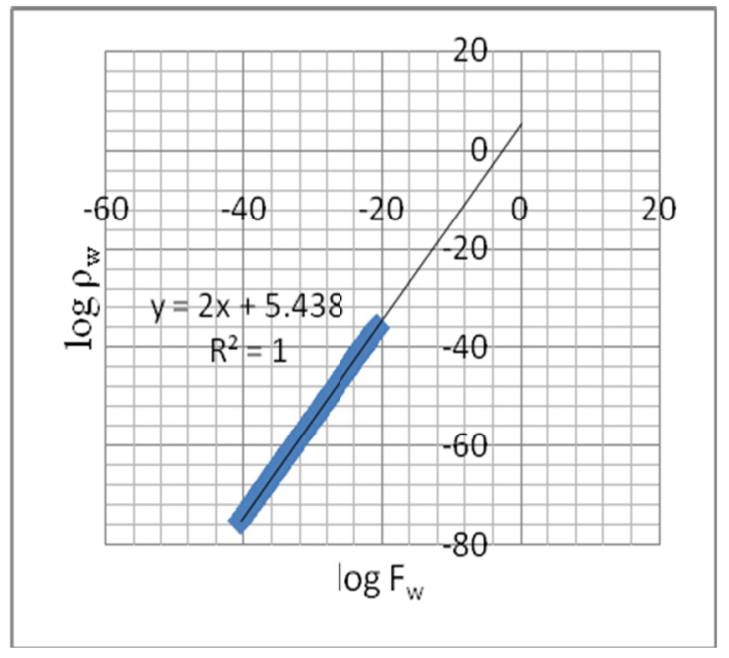

Figure 8. Plot of $\log \boldsymbol{\rho}_{\mathrm{w}}$ vs. $\log \mathrm{F}_{\mathrm{w}}$-wave

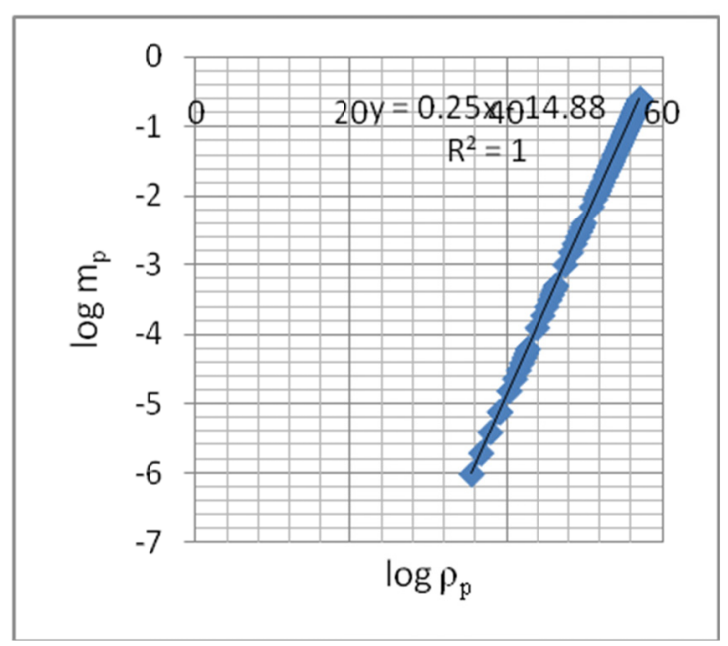

Figure 9. Plot of $\log \mathrm{m}_{\mathrm{p}}$ vs. $\log \boldsymbol{\rho}_{\mathrm{p}}$ - particle 
Table 2. A summary of some atomic physical properties

\begin{tabular}{|c|c|c|c|c|c|c|c|}
\hline & Atomic & Atomic & Angular & Centripetal & Elastic & Longtdnl. & \\
\hline & Radius & Density & Speed & Force & Modulus & Stress & Strain Rate \\
\hline Atom & $\mathrm{r} / \mathrm{m}$ & $\rho / \mathrm{kg} \mathrm{m}^{-3}$ & $\omega / \mathrm{rad} \mathrm{s}^{-1}$ & $\mathrm{~F} / \mathrm{N}$ & $\epsilon / \mathrm{Pa}$ & $\sigma / \mathrm{Pa}$ & $\tau / \%$ \\
\hline \multicolumn{8}{|c|}{ Absolute Ref. Frame microcosmic waveforms $U_{\text {abs }}^{*}$} \\
\hline $\mathrm{Ab}(\mathrm{e})$ & $1.4990 \mathrm{E}+08$ & $5.2258 \mathrm{E}-76$ & $6.2832 \mathrm{E}+00$ & $4.3628 \mathrm{E}-41$ & $2.9105 \mathrm{E}-49$ & $6.1806 \mathrm{E}-58$ & $2.1235 \mathrm{E}-07$ \\
\hline $\mathrm{H}$ & $7.3192 \mathrm{E}+04$ & $9.1933 \mathrm{E}-63$ & $1.2868 \mathrm{E}+04$ & $1.8299 \mathrm{E}-34$ & $2.5001 \mathrm{E}-39$ & $1.0873 \mathrm{E}-44$ & $4.3490 \mathrm{E}-04$ \\
\hline $\mathrm{C}$ & $9.1489 \mathrm{E}+03$ & $3.7656 \mathrm{E}-59$ & $1.0294 \mathrm{E}+05$ & $1.1711 \mathrm{E}-32$ & $1.2801 \mathrm{E}-36$ & $4.4536 \mathrm{E}-41$ & $3.4792 \mathrm{E}-03$ \\
\hline $\mathrm{Si}$ & $1.1436 \mathrm{E}+03$ & $1.5424 \mathrm{E}-55$ & $8.2355 \mathrm{E}+05$ & 7.4952E-31 & $6.5540 \mathrm{E}-34$ & $1.8242 \mathrm{E}-37$ & $2.7834 \mathrm{E}-02$ \\
\hline $\mathrm{Fe}$ & $7.1476 \mathrm{E}+01$ & $1.0108 \mathrm{E}-50$ & $1.3177 \mathrm{E}+07$ & $1.9188 \mathrm{E}-28$ & $2.6845 \mathrm{E}-30$ & $1.1955 \mathrm{E}-32$ & 4.4534E-01 \\
\hline $\mathrm{Br}$ & $3.8121 \mathrm{E}+01$ & $1.2493 \mathrm{E}-49$ & $2.4706 \mathrm{E}+07$ & $6.7457 \mathrm{E}-28$ & $1.7696 \mathrm{E}-29$ & $1.4776 \mathrm{E}-31$ & $8.3501 \mathrm{E}-01$ \\
\hline $\mathrm{Ba}$ & $1.1168 \mathrm{E}+00$ & $1.6959 \mathrm{E}-43$ & $8.4331 \mathrm{E}+08$ & 7.8593E-25 & 7.0373E-25 & $2.0057 \mathrm{E}-25$ & $2.8502 \mathrm{E}+01$ \\
\hline $\mathrm{Ta}$ & $2.5071 \mathrm{E}-01$ & $6.6774 \mathrm{E}-41$ & $3.7566 \mathrm{E}+09$ & $1.5595 \mathrm{E}-23$ & $6.2203 \mathrm{E}-23$ & $7.8974 \mathrm{E}-23$ & $1.2696 \mathrm{E}+02$ \\
\hline $\mathrm{Rn}$ & $1.3960 \mathrm{E}-01$ & $6.9463 \mathrm{E}-40$ & $6.7465 \mathrm{E}+09$ & $5.0300 \mathrm{E}-23$ & $3.6031 \mathrm{E}-22$ & $8.2155 \mathrm{E}-22$ & $2.2801 \mathrm{E}+02$ \\
\hline $\mathrm{U}$ & $3.1023 \mathrm{E}-02$ & $2.8484 \mathrm{E}-37$ & $3.0359 \mathrm{E}+10$ & $1.0186 \mathrm{E}-21$ & $3.2833 \mathrm{E}-20$ & $3.3689 \mathrm{E}-19$ & $1.0261 \mathrm{E}+03$ \\
\hline $\mathrm{Am}$ & $2.3267 \mathrm{E}-02$ & $9.0024 \mathrm{E}-37$ & $4.0479 \mathrm{E}+10$ & $1.8108 \mathrm{E}-21$ & 7.7827E-20 & $1.0647 \mathrm{E}-18$ & $1.3681 \mathrm{E}+03$ \\
\hline \multicolumn{8}{|c|}{ Visible Ref. Frame -macrocosmic particulate forms $U_{r}^{0}$} \\
\hline $\mathrm{Ab}(\mathrm{e})$ & $9.1312 \mathrm{E}-15$ & $3.0622 \mathrm{E}+35$ & $1.2783 \mathrm{E}+01$ & $1.4570 \mathrm{E}-18$ & $1.5957 \mathrm{E}-04$ & $5.5625 \mathrm{E}+09$ & $3.4860 \mathrm{E}+15$ \\
\hline $\mathrm{H}$ & $4.4586 \mathrm{E}-18$ & $5.3871 \mathrm{E}+48$ & $2.6179 \mathrm{E}+04$ & $6.1113 \mathrm{E}-12$ & $1.3707 \mathrm{E}+06$ & $9.7857 \mathrm{E}+22$ & $7.1393 \mathrm{E}+18$ \\
\hline $\mathrm{C}$ & $7.4248 \mathrm{E}-19$ & $7.0050 \mathrm{E}+51$ & $1.5721 \mathrm{E}+05$ & $2.2037 \mathrm{E}-10$ & $2.9681 \mathrm{E}+08$ & $1.2725 \mathrm{E}+26$ & $4.2871 \mathrm{E}+19$ \\
\hline $\mathrm{Si}$ & $3.1745 \mathrm{E}-19$ & $2.0962 \mathrm{E}+53$ & $3.6768 \mathrm{E}+05$ & $1.2055 \mathrm{E}-09$ & $3.7975 \mathrm{E}+09$ & $3.8078 \mathrm{E}+27$ & $1.0027 \mathrm{E}+20$ \\
\hline $\mathrm{Fe}$ & $1.5966 \mathrm{E}-19$ & $3.2759 \mathrm{E}+54$ & $7.3105 \mathrm{E}+05$ & 4.7656E-09 & $2.9848 \mathrm{E}+10$ & $5.9507 \mathrm{E}+28$ & $1.9936 \mathrm{E}+20$ \\
\hline $\mathrm{Br}$ & $1.1160 \mathrm{E}-19$ & $1.3722 \mathrm{E}+55$ & $1.0459 \mathrm{E}+06$ & 9.7537E-09 & $8.7395 \mathrm{E}+10$ & $2.4926 \mathrm{E}+29$ & $2.8521 \mathrm{E}+20$ \\
\hline $\mathrm{Ba}$ & $6.4932 \mathrm{E}-20$ & $1.1976 \mathrm{E}+56$ & $1.7976 \mathrm{E}+06$ & 2.8814E-08 & $4.4376 \mathrm{E}+11$ & $2.1754 \mathrm{E}+30$ & $4.9022 \mathrm{E}+20$ \\
\hline $\mathrm{Ta}$ & $4.9280 \mathrm{E}-20$ & $3.6097 \mathrm{E}+56$ & $2.3685 \mathrm{E}+06$ & $5.0025 \mathrm{E}-08$ & $1.0151 \mathrm{E}+12$ & $6.5570 \mathrm{E}+30$ & $6.4593 \mathrm{E}+20$ \\
\hline $\mathrm{Rn}$ & 4.0167E-20 & $8.1780 \mathrm{E}+56$ & $2.9059 \mathrm{E}+06$ & 7.5297E-08 & $1.8746 \mathrm{E}+12$ & $1.4855 \mathrm{E}+31$ & $7.9246 \mathrm{E}+20$ \\
\hline $\mathrm{U}$ & $3.7462 \mathrm{E}-20$ & $1.0808 \mathrm{E}+57$ & $3.1157 \mathrm{E}+06$ & $8.6564 \mathrm{E}-08$ & $2.3107 \mathrm{E}+12$ & $1.9634 \mathrm{E}+31$ & $8.4968 \mathrm{E}+20$ \\
\hline Am & $3.6696 \mathrm{E}-20$ & $1.1740 \mathrm{E}+57$ & $3.1808 \mathrm{E}+06$ & $9.0217 \mathrm{E}-08$ & $2.4585 \mathrm{E}+12$ & $2.1325 \mathrm{E}+31$ & $8.6742 \mathrm{E}+20$ \\
\hline \multicolumn{8}{|c|}{ Invs. Ref. Frame - microcosmic particulate forms $U_{\mathrm{r}}^{*} / U_{\mathrm{r}}^{\prime}$} \\
\hline $\mathrm{Ab}(\mathrm{e})$ & $1.8262 \mathrm{E}-14$ & $1.9139 \mathrm{E}+34$ & $6.3914 \mathrm{E}+00$ & $3.6426 \mathrm{E}-19$ & $1.9946 \mathrm{E}-05$ & $3.4766 \mathrm{E}+08$ & $1.7430 \mathrm{E}+15$ \\
\hline $\mathrm{H}$ & 8.9171E-18 & $3.3669 \mathrm{E}+47$ & $1.3090 \mathrm{E}+04$ & $1.5278 \mathrm{E}-12$ & $1.7134 \mathrm{E}+05$ & $6.1161 \mathrm{E}+21$ & $3.5696 \mathrm{E}+18$ \\
\hline $\mathrm{C}$ & $2.2237 \mathrm{E}-18$ & $8.7058 \mathrm{E}+49$ & $5.2489 \mathrm{E}+04$ & $2.4568 \mathrm{E}-11$ & $1.1048 \mathrm{E}+07$ & $1.5814 \mathrm{E}+24$ & $1.4314 \mathrm{E}+19$ \\
\hline $\mathrm{Si}$ & $2.4832 \mathrm{E}-19$ & $5.5988 \mathrm{E}+53$ & $4.7004 \mathrm{E}+05$ & $1.9702 \mathrm{E}-09$ & $7.9340 \mathrm{E}+09$ & $1.0170 \mathrm{E}+28$ & $1.2819 \mathrm{E}+20$ \\
\hline $\mathrm{Fe}$ & $9.2105 \mathrm{E}-21$ & $2.9580 \mathrm{E}+59$ & $1.2673 \mathrm{E}+07$ & $1.4321 \mathrm{E}-06$ & $1.5548 \mathrm{E}+14$ & $5.3733 \mathrm{E}+33$ & $3.4559 \mathrm{E}+21$ \\
\hline $\mathrm{Br}$ & $4.8460 \mathrm{E}-21$ & $3.8601 \mathrm{E}+60$ & $2.4086 \mathrm{E}+07$ & $5.1732 \mathrm{E}-06$ & $1.0675 \mathrm{E}+15$ & $7.0119 \mathrm{E}+34$ & $6.5685 \mathrm{E}+21$ \\
\hline $\mathrm{Ba}$ & $1.3635 \mathrm{E}-22$ & $6.1590 \mathrm{E}+66$ & $8.5604 \mathrm{E}+08$ & $6.5345 \mathrm{E}-03$ & $4.7924 \mathrm{E}+19$ & $1.1188 \mathrm{E}+41$ & $2.3345 \mathrm{E}+23$ \\
\hline $\mathrm{Ta}$ & $3.0564 \mathrm{E}-23$ & $2.4394 \mathrm{E}+69$ & $3.8189 \mathrm{E}+09$ & $1.3005 \mathrm{E}-01$ & $4.2549 \mathrm{E}+21$ & $4.4313 \mathrm{E}+43$ & $1.0414 \mathrm{E}+24$ \\
\hline $\mathrm{Rn}$ & $1.7015 \mathrm{E}-23$ & $2.5397 \mathrm{E}+70$ & $6.8598 \mathrm{E}+09$ & 4.1961E-01 & $2.4661 \mathrm{E}+22$ & $4.6133 \mathrm{E}+44$ & $1.8707 \mathrm{E}+24$ \\
\hline $\mathrm{U}$ & $3.7800 \mathrm{E}-24$ & $1.0428 \mathrm{E}+73$ & $3.0879 \mathrm{E}+10$ & $8.5026 \mathrm{E}+00$ & $2.2494 \mathrm{E}+24$ & $1.8942 \mathrm{E}+47$ & $8.4210 \mathrm{E}+24$ \\
\hline $\mathrm{Am}$ & $2.8349 \mathrm{E}-24$ & $3.2960 \mathrm{E}+73$ & $4.1173 \mathrm{E}+10$ & $1.5116 \mathrm{E}+01$ & $5.3323 \mathrm{E}+24$ & $5.9872 \mathrm{E}+47$ & $1.1228 \mathrm{E}+25$ \\
\hline
\end{tabular}




\subsection{General Observations}

\subsubsection{Angular Momentum and Torque}

Expectedly, the isolated atom's angular momentum $\mathbf{p}\left(\mathrm{mr}^{2} \omega\right)$ is constant regardless of mass, the value $\mathbf{p}=$ $1.040820574 \times 10^{-33} \mathrm{~kg} \mathrm{~m}^{2} \mathrm{rad} \mathrm{s}^{-1}$ is surprisingly common to both atomic wave and particulate forms; however, the two forms have different torque $\left(\mathrm{mr}^{3} \omega^{2}\right)$ values, $\mathbf{T}=9.80272 \times 10^{-25}$ for the wave and $1.21486 \times 10^{-46} \mathrm{~kg} \mathrm{~m}{ }^{3}$ $\left(\mathrm{rad} \mathrm{s}^{-1}\right)^{2}$ for the particulate form.

\subsubsection{Geometric Constants: $\pi, 1 / \pi \& 2 \pi$}

The results are consistent with the expression $\mathrm{v}=\pi \mathrm{c}=\mathrm{r} \omega$ where $\mathrm{v}$ is tangential velocity of the transverse e-m radiation $\mathrm{c}$; in other words, speed of light is the atomic waveform invariant e-m transverse radiation $\mathrm{c}=\mathrm{r}_{\mathrm{w}} \omega_{\mathrm{w}} / \pi$. Using, e.g., $\mathrm{r}_{\mathrm{e}(\mathrm{w})}=1.49896229 \times 10^{8} \mathrm{~m}$ and $\omega_{\mathrm{e}(\mathrm{w})}=6.283185308 \mathrm{rad} / \mathrm{s}$; velocity (not speed) of light in vacuum $\mathrm{v}_{\mathrm{w}}=9.418257784 \times 10^{8} \mathrm{~m} / \mathrm{s}$ giving pi $\pi=\mathrm{v} / \mathrm{c}=3.141592654$, in perfect agreement with the consensus value. We have shown earlier, Obande (2015a), that c's equivalent for particulate matter is $c^{0}$, which we suggest be called "de Broglie" radiation; its value is $\mathrm{c}^{\mathrm{o}}=3.715352291 \times 10^{-14} \mathrm{~m} / \mathrm{s}$. Using this value with particulate electron as example, we have $r_{e(p)}=9.131159995 \times 10^{-15} \mathrm{~m}, \omega_{e(p)}=12.782738959 \mathrm{rad} / \mathrm{s}$ and $\mathrm{v}_{\mathrm{p}}=1.16721234 \times 10^{-13} \mathrm{~m} / \mathrm{s}(\mathrm{see}$ Table 2) giving $\pi=\mathrm{v}_{\mathrm{p}} / \mathrm{c}^{\mathrm{o}}=3.141592635$, again in excellent agreement with the accepted value. This specific result re-affirms that $\mathrm{c}^{\mathrm{o}}$ is truly transverse radiation of particulate matter, it is the $C M B$, see Obande (2015c). Furthermore, strain $\tau_{\mathrm{p}}$ correlates with radius $\mathrm{r}_{\mathrm{p}}$ to give $\tau_{\mathrm{p}} \mathrm{r}_{\mathrm{p}}=\mathrm{k}=0.318419752 \cong 1 / \pi$ and angular speed correlates with frequency to give $\omega_{\mathrm{p}} / \vartheta_{\mathrm{p}}=\mathrm{k}=6.280583588 \cong 2 \pi$. Values of these constants would suggest that most (possibly all) physical constants are correlation coefficients of interacting SHM parameters of atomic e-m oscillation.

\section{Summary}

i. Most physical constants, possibly all, are correlation coefficients of interacting parameters of intrinsic e-m radiations that define the atom; all those investigated present in conical sections indicating that geometry of the causal e-m fields must be cones.

ii. Newtonian gravitation $\mathrm{G}$ is a waveform phenomenon, particulate matter is not implicated. The atomic waveform e-m flux density correlates with its radius and/or modulus to effect gravitation.

iii. Universal unit of (Galilean gravitational) acceleration $g$ is a phenomenon of both atomic wave and particulate matter. The following interactions give rise to $g$ : (a) centripetal force $F_{p}$ with atomic mass $m_{p}$; (b) atomic density $\rho_{\mathrm{p}}$ with atomic radius $\mathrm{r}_{\mathrm{p}}$; and (c) waveform modulus $\epsilon_{\mathrm{w}}$ with stress field $\sigma_{\mathrm{w}}$.

iv. An invariant $\mathrm{g}=7.943 \times 10^{59} \mathrm{~m} \mathrm{~s}^{-2} \mathrm{~kg}^{-1}$ binds matter together on atomic, stellar, galactic and cosmic scales. It is a waveform (bosonic) phenomenon attributable to the strong nuclear force (SNF) and would suggest that the SNF is not an electromagnetic but a mechanical force - an intrinsic extraordinary universal centripetal acceleration that holds matter together on all scales of existence.

v. In both atomic wave and particulate forms, rotational strain correlates with angular speed per unit radius to define electricity; for particulate atom, graphical analysis gives the correlation coefficient $\mathrm{k}=931.1078755 \times 10^{5}$ $\mathrm{eV}$ in line with CODATA $2014 \mathrm{amu} / \mathrm{MeV}=931.4940954$. The dimensions of $\mathrm{m} / \mathrm{eV}$, i.e., $\left(\mathrm{rad} \mathrm{s}^{-1} \mathrm{~m}^{-1}\right)^{1 / 2}$ would seem to identify with the spin quantum number $m_{s}= \pm \frac{1}{2}$.

vi. Magnetism is a phenomenon of both atomic wave and particulate forms. The waveform centripetal force $F_{w}$ interacts with rotational strain $\tau_{\mathrm{w}}$ to define electron magnetic moment $\mu_{\mathrm{e}}$ and with e-m flux density $\rho_{\mathrm{w}}$ to give atomic mass unit of magnetic flux amu/B. On the other hand the particulate atom's mass $m_{p}$ interacts with its material density $\rho_{\mathrm{p}}$ to give magnetic flux density B.

\section{Conclusion}

Compelling evidence has been produced to affirm simultaneous existence of the atom as wave and as particle. Some constants, e.g., G, $\mu_{\mathrm{e}}$ and $\mathrm{amu}$ of $\mathrm{B}$ are exclusive to the waveform while some, e.g., g, $\varepsilon, \lambda_{\mathrm{c}}$ and flux density B belong to particulate matter; yet both forms partake of others such as amu/eV. The use of the microwave ("de Broglie") radiation $c^{0}=3.715352291 \times 10^{-14} \mathrm{~m} / \mathrm{s}$ of particulate matter clearly facilitated the revelation here of existence of two broad groups of physical constants one having atomic waveform as causality and the other caused by atomic particulate form. Notably, in none of the constants investigated do we find the two forms collaborating to produce a given physical constant implying that the two forms are independent yet interactive as noted earlier (Obande, 2013). We repeat here that $\mathrm{c}^{\mathrm{o}}$ is the cosmic microwave background CMB radiation and it is none other than tangible (particulate) matter's intrinsic e-m radiation. This article belongs to a series of investigations aimed at explicitly defining atomic parameters and their interactions that give rise to 
observational effects; it has the aim to eventually work backwards and formulate a viable classical atomic physics theory capable of adding value to existing quantum physics formalisms with particular reference to conceptualizability. With the chemical elements' $\vartheta$ values reported recently, Obande (2015a), the present results and all others in the series can quite easily be verified.

\section{References}

CODATA. (2010). Recommended Values. Retrieved from http://physics.nist.gov/cgi-bin/cuu/value?

De Broglie, L. (1923). Waves and quanta. Nature, 112(2815), 540-540. http://www.dx.doi:10.1038/112540ao

Einstein, A. (1905). Does the Inertia of a Body Depend Upon its Energy Content? Annalen der physik, 28(13), 639. Retrieved from http://adsabs.havard.edu/abs/1905AnP... 323..693

Einstein, A. (1950). On the Generalized Theory of Gravitation. Scientific American, CLXXXII(4), 13-17.

Emiliani, C. (1995). Planet Earth, Cosmology, geology and evolution of life and environment. Cambridge, p.206.

Gao, L., Liang, J., Li, C., \& Wang, L. V. (2014). Single-shot compressed ultrafast photography at one hundred billion frames per second. Nature, 516(7529), 74-77.

Lorentz, H. A. (1899). Considerations on gravitation. Koninklijke Nederlandse Akademie van Wetenschappen Proceedings Series B Physical Sciences, 2, 559-574. Retrieved from http://en.wikisource.org/wiki/ Consideration_on_Gravitation

Lorentz, H. A. (1952). The Theory of Electrons (pp. 30-50). N.Y.: Dover.

Macken, J. A. (2011). The Universe is Only Spacetime. Retrieved from http://onlyspacetime.com

Obande, O. P. (2013). Notes on Russellian Cosmogony - Part 1: Absolute Atomic Mass. The Int. J. Engnr. \& Sci. 2(4), 68-77. Retrieved September 5, 2013 from http://www.theijes.com/papers/v2-i4/part.\%20(2)/M0242 068077.pdf

Obande, O. P. (2015a). Notes on Russellian cosmogony. II. A procedure for theoretical evaluation of relative atomic mass and internal energy. Phys. Essays, 28(1), 77. http://dx.doi.org/10.4006/0836-1398-28.1.78

Obande, O. P. (2015b). Classical mechanics analysis of the atomic wave and particulate forms. The Int. J. Engnr. \& Sci., 4(6), 1-11. Retrieved from http://www.theijes.com/vol,4,Issue,6.html

Obande, O. P. (2015c). Fundamental distinctions between velocity and speed of light. Submitted to Physics Essays (Sept. 2015).

Planck, M. (1901). Ueber des Gesetz der Energieverteilung im Normalspekrum. Annalen der Physik, 309(3), 553. In T. Ando (Trans.), On the law of the Distribution of Energy in the Normal Spectrum. Retrieved from http://theochem.kuchem.kyoto-u.ac.jp/Ando/planck1901.pdf

Renn, J. (2007). The Genesis of General Relativity vol. 4. Gravitation in the Twilight of Classical Physics: Between Mechanics, Field Theory and Astronomy. In J. Renn, \& M. Schemmel (eds.), Boston Studies in the Philosophy of Science (vol. 250). Dordrecht: Springer. Retrieved from http://www.springer.com/9780-8176-4939-5

Russell, W., \& Russell, L. (1981). Atomic Suicide (2nd ed.)? Virginia: Univ. Sci. \& Phil. Swannanoa.

Wilczek, F. (2012). Scientific American. Retrieved from http://www.scientificamerican.com/article.cfm?id =happy_birthday_electron

\section{Copyrights}

Copyright for this article is retained by the author(s), with first publication rights granted to the journal.

This is an open-access article distributed under the terms and conditions of the Creative Commons Attribution license (http://creativecommons.org/licenses/by/3.0/). 